\title{
Interannual variability of the stratospheric wave driving during northern winter
}

\author{
A. J. Haklander ${ }^{1,2}$, P. C. Siegmund ${ }^{3}$, and H. M. Kelder ${ }^{1,2}$ \\ ${ }^{1}$ Eindhoven University of Technology (TUE), Department of Applied Physics, P.O. Box 513, 5600 MB Eindhoven, The \\ Netherlands \\ ${ }^{2}$ Royal Netherlands Meteorological Institute (KNMI), Climate and Seismology Department, Climate Observation Division, \\ P.O. Box 201, 3730 AE De Bilt, The Netherlands \\ ${ }^{3}$ Royal Netherlands Meteorological Institute (KNMI), Climate and Seismology Department, Climate and Chemistry Division, \\ P.O. Box 201, 3730 AE De Bilt, The Netherlands
}

Received: 6 December 2006 - Published in Atmos. Chem. Phys. Discuss.: 5 January 2007

Revised: 16 March 2007 - Accepted: 8 May 2007 - Published: 16 May 2007

\begin{abstract}
The strength of the stratospheric wave driving during northern winter is often quantified by the JanuaryFebruary mean poleward eddy heat flux at $100 \mathrm{hPa}$, averaged over $40^{\circ}-80^{\circ} \mathrm{N}$ (or a similar area and period). Despite the dynamical and chemical relevance of the wave driving, the causes for its variability are still not well understood. In this study, ERA-40 reanalysis data for the period 1979-2002 are used to examine several factors that significantly affect the interannual variability of the wave driving. The total poleward heat flux at $100 \mathrm{hPa}$ is poorly correlated with that in the troposphere, suggesting a decoupling between $100 \mathrm{hPa}$ and the troposphere. However, the individual zonal wave-1 and wave- 2 contributions to the wave driving at $100 \mathrm{hPa}$ do exhibit a significant coupling with the troposphere, predominantly their stationary components. The stationary wave- 1 contribution to the total wave driving significantly depends on the latitude of the stationary wave-1 source in the troposphere. The results suggest that this dependence is associated with the varying ability of stationary wave- 1 activity to enter the tropospheric waveguide at mid-latitudes. The wave driving anomalies are separated into three parts: one part due to anomalies in the zonal correlation coefficient between the eddy temperature and eddy meridional wind, another part due to anomalies in the zonal eddy temperature amplitude, and a third part due to anomalies in the zonal eddy meridional wind amplitude. It is found that year-to-year variability in the zonal correlation coefficient between the eddy temperature and the eddy meridional wind is the most dominant
\end{abstract}

Correspondence to: A. J. Haklander

(haklande@knmi.nl) factor in explaining the year-to-year variability of the poleward eddy heat flux.

\section{Introduction}

According to the downward-control principle, the stratospheric residual meridional circulation at any level is controlled by the vertically-integrated zonal force due to breaking Rossby and gravity waves above that level (Haynes et al., 1991). The breaking waves deposit westward angular momentum into the relative and planetary angular momentum "reservoirs", causing a westward acceleration and a poleward displacement of the air (e.g., Andrews et al., 1987). In the low-frequency limit, the westward acceleration is zero and the meridional circulation is referred to as the BrewerDobson circulation (e.g., Shepherd, 2000). The term "downward control" can, however, be somewhat misleading, since it is predominantly the wave activity emanating from below that determines the amount of angular momentum deposited aloft.

The net zonal-mean upward flux of wave activity is represented by the upward component $F_{z}$ of the Eliassen-Palm (E-P) flux, which for quasigeostrophic flow is proportional to the zonal-mean poleward eddy heat flux $\left[v^{*} T^{*}\right]$, where the square brackets denote the zonal average and the asterisk denotes the deviation thereof (e.g. Andrews et al., 1987; Newman and Nash, 2000). In the lower stratosphere, $\left[v^{*} T^{*}\right]$ (and therefore $F_{z}$ ) exhibits a strong, positive correlation with the tendency of total ozone at mid- and high latitudes during northern winter (e.g., Fusco and Salby, 1999; Randel et al.,

Published by Copernicus GmbH on behalf of the European Geosciences Union. 
2002). Also, during late northern winter the midlatitude eddy heat flux in the lower stratosphere is highly and positively correlated with the temperature in early March at high latitudes, and consequently with the strength of the polar vortex (e.g., Newman et al., 2001; Polvani and Waugh, 2004). Both observations can be explained by the wave-induced poleward transport of ozone-rich air from the tropical source and the subsequent adiabatic compression at higher latitudes.

This fundamental link between the poleward eddy heat flux and the dynamics and chemistry of the stratosphere is now well understood and also quantitatively employed as a diagnostic to validate coupled chemistry-climate models (CCMs) (Austin et al., 2003; Eyring et al., 2005). Austin et al. used the $\left[v^{*} T^{*}\right]$ field at $100 \mathrm{hPa}$ averaged for JanuaryFebruary over $40^{\circ}-80^{\circ} \mathrm{N}$, hereafter referred to as $H_{100}$, as a measure of the net upward flux of midwinter wave activity in the lower stratosphere. They evaluated several CCMs with respect to $H_{100}$, the polar stratospheric temperatures in early spring, and the (almost linear) relationship between both diagnostics. Since almost all of the planetary wave activity crosses the $100 \mathrm{hPa}$ level between $40^{\circ}-80^{\circ} \mathrm{N}$ (Hu and Tung, 2003), $H_{100}$ indeed provides a good measure of the net total wave activity propagating into the stratosphere. Several studies have been performed to analyze trends in $H_{100}$ (or a similar diagnostic) over the last decades, and to predict future trends. Hu and Tung (2003) found a significant downward trend over 1979-2002 for [ $\left.v^{*} T^{*}\right]$ at $100 \mathrm{hPa}$, averaged over $50^{\circ}-90^{\circ} \mathrm{N}$ and January to March. Austin et al. (2003) compared future $\mathrm{H}_{100}$ trends in a number of enhanced- $\mathrm{CO}_{2}$ climate simulations, and found for most models a slightly negative trend over the next few decades, although at best of marginal statistical significance. One of the models showed a highly significant positive trend. For a doubled $\mathrm{CO}_{2}$ climate, Sigmond et al. (2004) computed a significant increase of the Northern Hemisphere (NH) stratospheric residual circulation during winter, corresponding to an increase of the poleward eddy heat flux. These examples illustrate that future predictions of $H_{100}$ are very uncertain. However, in a recent multi-model study by Butchart et al. (2006), increasing greenhouse gas concentrations were found to yield an overall strengthening of the Brewer-Dobson circulation and the associated wave driving, with the strongest trend in $\mathrm{NH}$ winter. Butchart et al. conclude that it remains an important future task to identify the causes of the increase in wave driving. Thus, despite the fact that it is widely acknowledged that the stratospheric wave driving has a large impact on the dynamics and chemistry of the stratosphere, the causes for its trends and variability are still not well understood.

In the present study, $H_{100}$ is used as a measure of the net total midwinter wave activity that propagates from the troposphere into the stratosphere, following Austin et al. (2003), and Eyring et al. (2005). Our analysis puts the emphasis on the interannual variability of $H_{100}$, in order to obtain a better understanding of the causes of this observed variability, at both the interannual and the decadal timescale. Year-to-year variations in $H_{100}$ can be attributed to many factors. The strength of the tropospheric wave source is an obvious factor, but also the shape of the source spectrum determines the amount of wave activity that reaches $100 \mathrm{hPa}$, as is described by the Charney-Drazin criterion (Charney and Drazin, 1961). This criterion states that stationary planetary waves can only propagate upward in a westerly zonal-mean flow that is not too strong. Only the longest waves can propagate through stronger westerlies, which implies that during winter only the longest waves can propagate into the stratosphere. The background zonal-mean flow determines the properties of this low-pass filter, and therefore also affects the interannual variability of $H_{100}$. The main goal of the present study is to investigate to what extent the year-to-year variability in $H_{100}$ is affected by several factors. The factors that are examined include the strength of the total upward wave activity flux in the troposphere, the shape of the wave activity spectrum, the latitude and height of the wave source, and the refractive properties of the background flow. It is also examined whether the zonal correlation coefficient between the meridional wind and the temperature has a significant effect on the interannual variability of $H_{100}$. Our analysis is based on ERA-40 reanalysis data for the period of 1979-2002. In Sect. 3, estimated values are often presented along with an error bar. These represent the associated standard deviations.

The structure of the paper is as follows. Section 2 gives a description of the data sources and discusses various ways of decomposing the poleward eddy heat flux. The main results are given in Sect. 3, and a summary and discussion of the results is presented in Sect. 4.

\section{Data and method}

\subsection{Data}

We use 6-hourly temperature and horizontal wind fields for 24 years (1979-2002) of ERA-40 reanalysis data (Simmons and Gibson, 2000). Although the ERA-40 dataset starts in 1957, we have only included the satellite era, from 1979 onwards, in our analysis. For this period, the global observation data coverage is considered to be good (Uppala et al., 2005). ERA-40 is produced by the European Centre for Medium-Range Weather Forecasts (ECMWF). The meteorological fields were retrieved for a lat-lon grid of $2.5^{\circ} \times 2.5^{\circ}$ between $0^{\circ}-90^{\circ} \mathrm{N}$, at 23 pressure levels between 1000 and $1 \mathrm{hPa}$.

\subsection{Linear regression analysis}

The total poleward eddy heat flux can be decomposed into the sum of several components, such as the stationary and transient wave components. The impact of each component on the interannual variability of the total heat flux can be evaluated by performing a linear regression analysis. This can be understood as follows. It can easily be shown that if 
$y \equiv \sum x_{i}$, then the variance of $y$ equals the sum of the covariances between $y$ and the $x_{i}$, i.e., $\operatorname{var}(y)=\sum \operatorname{cov}\left(x_{i}, y\right)$. Thus, $\operatorname{cov}\left(x_{i}, y\right)$ can be interpreted as the contribution of $x_{i}$ to $\operatorname{var}(y)$. If we define $b_{i} \equiv \operatorname{cov}\left(x_{i}, y\right) \operatorname{var}^{-1}(y)$, where $\sum b_{i}=1$, then $b_{i}$ is the regression coefficient for the linear least-squares fit given by $\tilde{x}_{i}=a_{i}+b_{i} y$. It should be noted that the correlation coefficient $r_{i}$ between $y$ and $x_{i}$ can be large, while the associated value of $b_{i}$ is small. For this reason, it is useful to consider both $b_{i}$ and $r_{i}$. In the present study, $y$ represents the total heat flux and the $x_{i}$ represent the various components of the total heat flux (see Sect. 2.3). Hereafter the phrase "a linear regression of $v_{1}$ with $v_{2}$ is performed" implies that $v_{1}$ is the independent and $v_{2}$ is the dependent variable.

\subsection{Decompositions of the heat flux}

The total poleward eddy heat flux, averaged over space and time, can be decomposed by separating the eddy meridional wind and eddy temperature into a stationary and a transient part. If we denote the temporal average over January and February by an overbar, the deviation thereof by a prime, and the cosine-latitude weighted spatial average between $40^{\circ}-$ $80^{\circ} \mathrm{N}$ by angle brackets, we can write $H$ at a certain pressure level as

$H \equiv<\overline{v^{*} T^{*}}>=<\bar{v}^{*} \bar{T}^{*}>+<\overline{v^{*} T^{* *}}>$,

where $H$ at $100 \mathrm{hPa}$ was previously denoted by $H_{100}$. The asterisk denotes the deviation of the zonal mean. The r.h.s. terms of Eq. (1) thus describe the contribution to $H$ by the stationary and transient eddies, respectively.

In addition to the temporal decomposition in Eq. (1), a spatial decomposition can be made by discriminating between the individual zonal wavenumber components of the heat flux. The zonal wave component of the total eddy heat flux is calculated as the product of the wave components of $v$ and $T, v_{s}$ and $T_{s}$ (e.g., Newman and Nash, 2000). This yields

$H=\sum_{s \geq 1}<\overline{v_{s} T_{s}}>$,

where the subscript $\mathrm{s}$ denotes the zonal wave-s component. Combining Eqs. (1) and (2) yields

$H=\sum_{s \geq 1}<\bar{v}_{s} \bar{T}_{s}>+\sum_{s \geq 1}<\overline{v_{s}^{\prime} T_{s}^{\prime}}>$.

The impact of these individual stationary and transient wave components on the interannual variability of the total heat flux will be evaluated by a linear regression analysis in the next section.

A different way of decomposing the total eddy heat flux, is by noting that $\left[v^{*} T^{*}\right]$ can be expressed as

$\left[v^{*} T^{*}\right]=r_{v, T} \sigma_{v} \sigma_{T}$, where $r_{v, T}$ is the zonal correlation coefficient, and $\sigma_{v}$ and $\sigma_{T}$ are the zonal standard deviations of $v$ and $T$. If $v$ or $T$ would consist of only one wave component, then their wave amplitudes would be given by $\sqrt{2} \sigma_{v}$ and $\sqrt{2} \sigma_{T}$, respectively, and $r_{v, T}$ would be equal to $\cos \Delta \varphi$, where $\Delta \varphi$ is the phase difference between the $v$ and the $T$ wave patterns. Therefore, $r_{v, T}$ might be considered as the cosine of the 'effective phase difference' between $v$ and $T$ for the total spectrum of waves, with $\sqrt{2} \sigma_{v}$ and $\sqrt{2} \sigma_{T}$ representing the effective $v$ and $T$ amplitudes, respectively. The larger $r_{v, T}$, the smaller the effective phase difference between the $v$ and $T$ fields, and the more efficiently heat is transported poleward by the waves. To investigate both the qualitative and the quantitative effects of year-to-year variations in $r_{v, T}, \sigma_{v}$, and $\sigma_{T}$ on the interannual variability of $H_{100}$, we use the following approach (e.g., Siegmund, 1995). First, we rewrite the average of Eq. (4) over $40^{\circ}-80^{\circ} \mathrm{N}$ and January-February as follows:

$H \equiv<\overline{r_{v, T} \sigma_{v} \sigma_{T}}>\equiv<\overline{r_{v, T}}><\overline{\sigma_{v}}><\overline{\sigma_{T}}>+\tilde{E} \equiv \tilde{H}+\tilde{E}$,

where $\tilde{E}$ denotes the error that is introduced by neglecting the zonal and temporal cross-correlations between $r_{v, T}, \sigma_{v}$, and $\sigma_{T}$. The validity of the approximation $H_{100} \approx \tilde{H}_{100}$ will be discussed in Sect. 4. Dropping the angular brackets and the overbars, denoting the 24-year mean by a superscript $m$ and the deviation thereof by a $\Delta, \Delta \tilde{H}$ can be linearized as:

$\Delta \tilde{H} \equiv \Delta \hat{H}+\Delta \hat{E} \equiv \sigma_{v}^{m} \sigma_{T}^{m} \Delta r_{v, T}+\sigma_{T}^{m} r_{v, T}^{m} \Delta \sigma_{v}+\sigma_{v}^{m} r_{v, T}^{m} \Delta \sigma_{T}+\Delta \hat{E}$,

where $\Delta \hat{E}$ denotes the error that arises from the linearization. If Eqs. (5) and (6) are combined, we obtain

$\Delta H \equiv \sigma_{v}^{m} \sigma_{T}^{m} \Delta r_{v, T}+\sigma_{T}^{m} r_{v, T}^{m} \Delta \sigma_{v}+\sigma_{v}^{m} r_{v, T}^{m} \Delta \sigma_{T}+\Delta \hat{E}+\Delta \tilde{E}$.

Equation (7) will be used to analyze the contribution to the interannual variability of $H_{100}$ by the interannual variabilities of $r_{v, T}, \sigma_{v}$, and $\sigma_{T}$.

\section{Results}

\subsection{Timeseries of $H_{100}$}

The timeseries of $H_{100}$ (1979-2002) is displayed as the thick solid line with filled circles in Fig. 1. During this 24-year period, $H_{100}$ ranged between 11.2 and $19.2 \mathrm{~K} \mathrm{~m} \mathrm{~s}^{-1}$, and the average value of $H_{100}$ was $15.1 \pm 0.5 \mathrm{~K} \mathrm{~m} \mathrm{~s}^{-1}$. There is a slightly negative trend in $H_{100}$, but the trend is not statistically significant $(93.2 \%$ confidence level). Hu and Tung (2003) did find a highly significant downward trend over 1979-2002 in the vertical EP-flux component north of $50^{\circ} \mathrm{N}$ for the January-March period, which was suggested to be due to the effect of Arctic ozone depletion during late winter and spring. This effect is likely smaller for $H_{100}$, which is the average over the January-February period. If we regard $H_{100}$ as the sum of its zonal wave-s components as expressed by Eq. (2), we find that the $s=1-3$ components of $H_{100}$ account for more than $90 \%$ of $H_{100}$. The first three wave components 


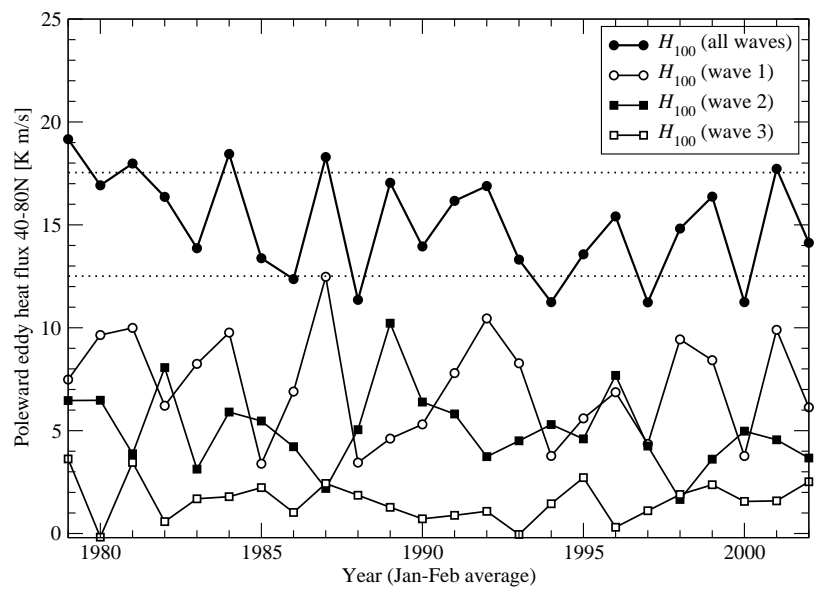

Fig. 1. Poleward eddy heat flux at $100 \mathrm{hPa}$, averaged over $40^{\circ}-$ $80^{\circ} \mathrm{N}$ and January-February, for the years 1979-2002. The sum of all wave contributions $H_{100}$ is shown, as well as the separate wavenumber 1-3 components of $H_{100}$.

Table 1. Linear regression coefficients \pm their standard error, and correlation coefficients for the linear regression of $H_{100}$ with its total, stationary and transient $\mathrm{s}=1-5$ components. The linear regression is performed over 1979-2002.

\begin{tabular}{lllllll}
\hline \multirow{2}{*}{$s$} & \multicolumn{3}{c}{ Regr. coeff. $\left(b_{i}\right)$} & \multicolumn{3}{c}{ Corr. coeff. $\left(r_{i}\right)$} \\
\cline { 2 - 7 } & Tot $\pm \sigma$ & Stat $\pm \sigma$ & Tran $\pm \sigma$ & Tot & Stat & Tran \\
\hline 1 & $0.74 \pm 0.15$ & $0.56 \pm 0.23$ & $0.18 \pm 0.14$ & 0.73 & 0.47 & 0.26 \\
2 & $0.12 \pm 0.16$ & $0.06 \pm 0.16$ & $0.06 \pm 0.08$ & 0.16 & 0.08 & 0.15 \\
3 & $0.09 \pm 0.08$ & $0.02 \pm 0.08$ & $0.08 \pm 0.05$ & 0.24 & 0.05 & 0.30 \\
4 & $0.00 \pm 0.03$ & $-0.02 \pm 0.02$ & $0.02 \pm 0.03$ & 0.01 & -0.19 & 0.13 \\
5 & $0.00 \pm 0.02$ & $0.00 \pm 0.00$ & $-0.01 \pm 0.02$ & -0.04 & 0.23 & -0.09 \\
all & 1 & $0.63 \pm 0.16$ & $0.37 \pm 0.16$ & 1 & 0.65 & 0.46 \\
\hline
\end{tabular}

of $H_{100}$ are also shown in Fig. 1. Both the variance and the 24-year average decrease with increasing wavenumber. For the majority of the years, variations in $H_{100}$ seem to be dominated by the wave- 1 variations, indicated by the line with open circles in Fig. 1. A relatively constant factor is that the wave- 1 and wave- 2 variations tend to be opposite. The correlation coefficient for the wave- 1 and wave- 2 components is $r=-0.42$, which is significant at a $95.8 \%$ confidence level. The separate $\mathrm{s}=1,2$, and 3 components of $H_{100}$ all exhibit a slightly negative trend over 1979-2002, but the statistical significance of these trends is well below the $95 \%$ confidence level.

\subsection{Wave contributions to interannual variability of $H_{100}$}

To further examine the interannual variability of $H_{100}$, we decompose $H_{100}$ into its stationary and transient wave components, as expressed by Eq. (3). Taking $H_{100}$ as the independent variable, the linear regression coefficient $b_{i}$ for

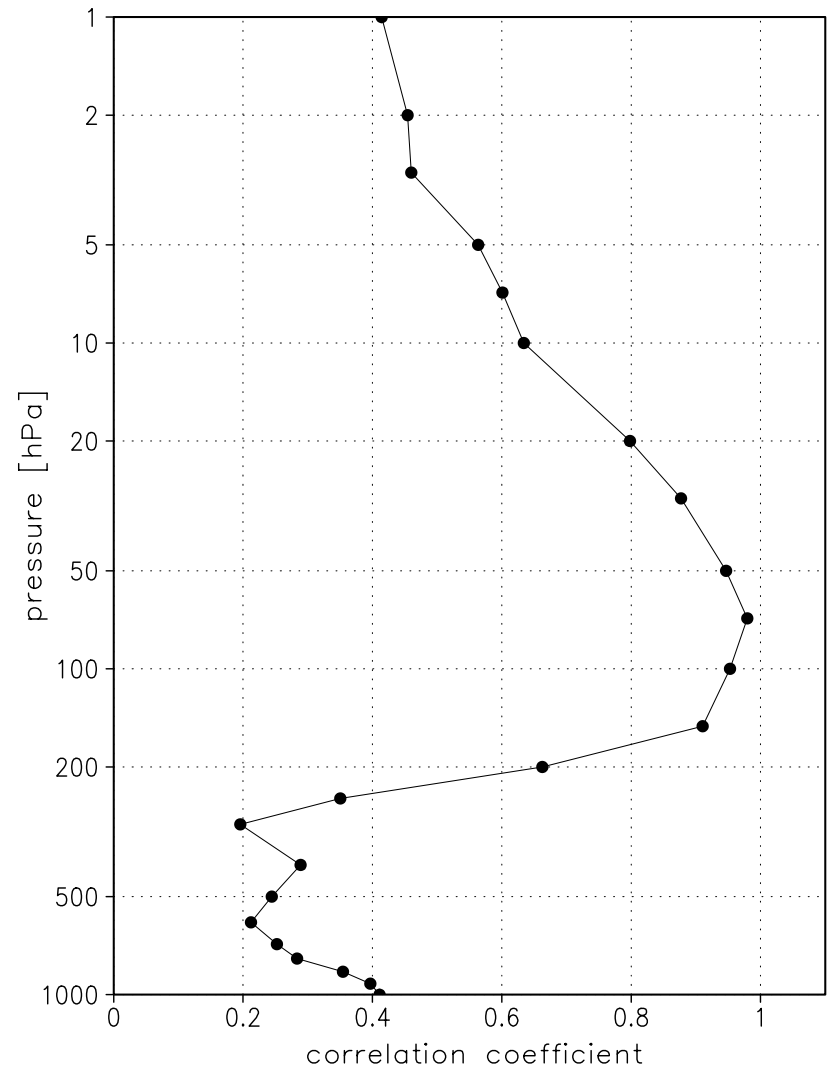

Fig. 2. Correlation coefficients of $H_{100}$ with $<\overline{v^{*} T^{*}}>_{N H}$. Correlation coefficients are calculated over the years 1979-2002.

the regression of $H_{100}$ with its stationary or transient wave component represents the relative contribution by that wave component to the total variance of $H_{100}$, as discussed in Sect. 2. Table 1 shows the regression coefficients and the corresponding correlation coefficients for the total (stationary plus transient), stationary, and transient wave 1-5 components of $H_{100}$. Using a Student's $t$-test, we find for a sample size of 24 , that the correlation coefficient $r_{i}$ is significantly different from zero at a $>95 \%, 99 \%$, or $99.9 \%$ confidence level if $\left|r_{i}\right|>0.40,0.52$ or 0.63 , respectively. The sum of the regression coefficients for the total wave 1-5 contribution to $H_{100}$ is $0.95 \pm 0.05$, with a corresponding correlation coefficient $r_{i}=0.996$ (not shown). Therefore, wavenumbers 6 and higher can be neglected in the analysis of the interannual variability of $H_{100}$. In fact, almost all of the interannual variability of $H_{100}$ is due to $s=1-3$, with a combined regression coefficient of $b_{i}=0.96 \pm 0.06$ and $r_{i}=0.98$. Only retaining $\mathrm{s}=1,2$ yields $b_{i}=0.86 \pm 0.11$ and $r_{i}=0.88$. We can thus state that about $85 \%$ of the interannual variability of $H_{100}$ can be attributed to its $s=1,2$ components. When analyzing the interannual variability of $H_{100}$, it is sufficient to only consider wavenumbers $s=1-3$, or perhaps even $s=1,2$. The bottom row of Table 1 clearly shows that the interannual variability of $H_{100}$ is dominated by the stationary waves, with 
$b_{i}=0.63 \pm 0.16$ and $r_{i}=0.65$. However, the correlation coefficient of $H_{100}$ with its transient component is also significant at the $97.6 \%$ confidence level.

\subsection{Vertical coupling}

As described in the introduction, $H_{100}$ is proportional to the total net wave activity flux emanating from below between $40^{\circ} \mathrm{N}$ and $80^{\circ} \mathrm{N}$ at the $100 \mathrm{hPa}$ level. Most of the planetary wave activity that constitutes $H_{100}$ has propagated upward from its tropospheric source, and therefore, it is expected that $H_{100}$ has a significant positive correlation coefficient with the poleward eddy heat flux at levels below (and above) $100 \mathrm{hPa}$. To verify this, we examine the amount of vertical coupling between $100 \mathrm{hPa}$ and other levels. We do this by calculating the vertical profile of the correlation coefficient of $H_{100}$ with $<\overline{v^{*} T^{*}}>_{N H}$, which we define as the $20^{\circ}-$ $90^{\circ} \mathrm{N}$ average of [ $\overline{v^{*} T^{*}}$ ], at levels from $1000 \mathrm{hPa}$ to $1 \mathrm{hPa}$. We compute the correlation coefficients with $\left\langle\overline{v^{*} T^{*}}\right\rangle_{N H}$, since the wave activity flux contributing to $H_{100}$ may have partially originated from, or may propagate into, latitudes outside the $40^{\circ}-80^{\circ} \mathrm{N}$ band. The correlation coefficient profile is shown in Fig. 2. At $100 \mathrm{hPa}, H_{100}$ is highly correlated with $\left\langle\overline{v^{*} T^{*}}>_{N H}(r=0.95)\right.$, suggesting that the $100 \mathrm{hPa}$ wave activity outside the $40^{\circ}-80^{\circ} \mathrm{N}$ area is relatively small. This is confirmed by the fact that $H_{100}$ accounts for about $90 \%$ of $<\overline{v^{*} T^{*}}>_{N H}$ at $100 \mathrm{hPa}$ in the $1979-2002$ period. Therefore, to simplify the interpretation of our results, we neglect the $100 \mathrm{hPa}$ upward wave activity flux at latitudes outside the $40^{\circ}-80^{\circ} \mathrm{N}$ window. In Fig. 2 , we see that the level of maximum correlation coefficient between $H_{100}$ and $\left\langle\overline{v^{*} T^{*}}\right\rangle_{N H}$ is found at $70 \mathrm{hPa}$ rather than $100 \mathrm{hPa}$. Above $70 \mathrm{hPa}$, the correlation coefficient gradually decreases to marginally significant values near the stratopause $\sim 1 \mathrm{hPa}$. Below $100 \mathrm{hPa}$, the correlation coefficient falls off quite rapidly, and is not significant $(|r|<0.40)$ below $200 \mathrm{hPa}$. Thus, there exists a decoupling between variations in the total upward flux of wave activity in the troposphere (below $200 \mathrm{hPa}$ ) and variations at $100 \mathrm{hPa}$. Assuming that the wave sources are predominantly located in the troposphere, this decoupling can be understood as follows. Suppose an amount of wave activity propagates upward in the $\mathrm{NH}$ at some tropospheric pressure level $p$ during January-February. A fraction $\alpha_{p}$ of this wave activity is absorbed below $100 \mathrm{hPa}$, where $\alpha_{p}$ lies between 0 and 1 . Assuming that no wave activity crosses the equator, the remaining fraction of the wave activity $\left(1-\alpha_{p}\right)$ thus reaches the $100-\mathrm{hPa}$ level and contributes to $H_{100}$. If $\alpha_{p}$ is less than one and independent of time, then the correlation coefficient between $H_{100}$ and the wave activity flux at pressure level $p$ will be one. On the other hand, if $\alpha_{p}$ has a large interannual variability, the correlation coefficient will be small.

For a plane and conservative planetary wave, the zonal wavenumber $\mathrm{s}$ and the frequency remain constant along its path (or "ray") in the meridional plane (e.g., Karoly and
Hoskins, 1982). Therefore, it makes sense to repeat the previous analysis for each individual zonal wave component. To examine the amount of vertical coupling as a function of zonal wavenumber (stationary plus transient), we compute the correlation coefficients of the wave-s component of $H_{100}$ with the (same) wave-s component of $\left\langle\overline{v^{*} T^{*}}\right\rangle_{N H}$ at other levels. We perform this analysis for the individual wavenumbers 1 to 5 and $6+$, separately. The results are shown in Fig. 3a. The $s=1$ component of $\left\langle\overline{v^{*} T^{*}}\right\rangle_{N H}$ is significantly correlated with the $\mathrm{s}=1$ component of $H_{100}$ at $500 \mathrm{hPa}$, and at all levels above $400 \mathrm{hPa}$. The $\mathrm{s}=2$ component of $\left\langle\overline{v^{*} T^{*}}\right\rangle_{N H}$ exhibits a significant correlation with the $s=2$ component of $H_{100}$ throughout the troposphere and the stratosphere. Note that the wave- 2 correlation coefficient reaches a minimum in the mid-troposphere but that the correlation coefficients for $\mathrm{s}=2$ are statistically significant at all levels below $1 \mathrm{hPa}$. For waves with $s>2$, the correlation coefficients generally only exceed the $95 \%$ significance level between $250 \mathrm{hPa}$ and $50 \mathrm{hPa}$. Thus, the lack of correlation we saw in Fig. 2 between the total upward flux of wave activity in the troposphere and that at $100 \mathrm{hPa}$ is also observed for the $\mathrm{s}>2$ flux components, but not (entirely) for $s=1,2$. This result implies that a significant part of the interannual variability in the $\mathrm{s}$ $=1,2$ components of $H_{100}$ is due to year-to-year variations in the strength of the $s=1,2$ wave source in the troposphere. There is no significant correlation for the $s>2$ flux components, since the refractive index for those waves exhibits a vertical layer of negative values in the lower stratosphere (Fig. 5b). Therefore, meridional refraction and reflection of the $s>2$ waves is taking place below $100 \mathrm{hPa}$, so that $H_{100}$ is dominated by waves 1 and 2 .

We have just shown that the separate $s=1,2$ components of $H_{100}$, to which about $85 \%$ of the interannual variability of $H_{100}$ can be attributed, are significantly correlated with the separate $\mathrm{s}=1,2$ components of $\left\langle\overline{v^{*} T^{*}}\right\rangle_{N H}$ in the troposphere. But to what extent can the interannual variability of the total $H_{100}$ be attributed to year-to-year variations in the separate $\mathrm{s}=1$ and $\mathrm{s}=2$ components (or higher) of $<\overline{v^{*} T^{*}}>_{N H}$ in the troposphere? To answer this question, we examine the correlation coefficient of $H_{100}$ (i.e., the sum of all wave components) with the separate wave components of $<\overline{v^{*} T^{*}}>_{N H}$. The results are shown in Fig. $3 \mathrm{~b}$, where the wavenumber of the pressure-dependent $\left.<\overline{v^{*} T^{*}}\right\rangle_{N H}$ component is given along the horizontal axis. At levels below $200 \mathrm{hPa}$, the $\mathrm{s}=1,2$ components of $\left\langle\overline{v^{*} T^{*}}>_{N H}\right.$ are not significantly correlated with $H_{100}$. In fact, none of the wave components is. However, in the upper stratosphere, the $s=4$ component of $<\overline{v^{*} T^{*}}>_{N H}$ exhibits a remarkably strong correlation with $H_{100}$. It is interesting to compare Figs. 3a and 3b. We observe in Fig. 3a that the wave- 4 component of $<\overline{v^{*} T^{*}}>_{N H}$ in the upper stratosphere is not at all correlated with the wave-4 component of $H_{100}$. However, Fig. 3 b shows that the correlation coefficient with the total $H_{100}$ is highly significant for the wave-4 component of $\left\langle\overline{v^{*} T^{*}}\right\rangle_{N H}$ in the upper stratosphere ( $r=0.58$ at $2 \mathrm{hPa}, 99.7 \%$ confidence level). 

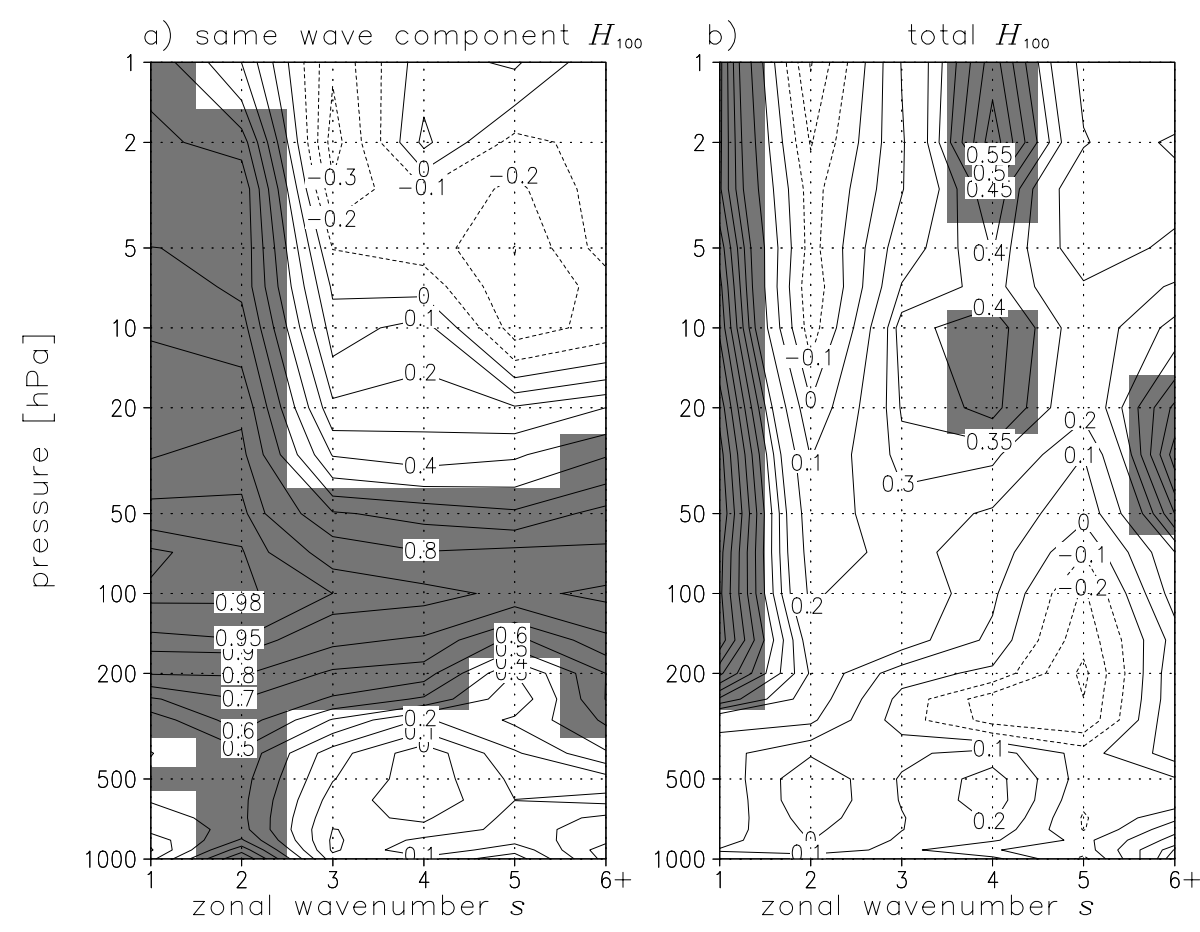

Fig. 3. Correlation coefficients of (a) the zonal wave-s component of $H_{100}$, and (b) $H_{100}$, with the zonal wave-s component of $<\overline{v^{*} T^{*}}>N H$. Correlation coefficients are calculated over 1979-2002, and the areas with $>95 \%$ confidence levels are shaded.

The results suggest that wavenumber 4 is a preferred mode for the breaking of very long planetary waves in the upper stratosphere.

\subsection{Correlation patterns in the meridional plane}

Thusfar, we have only considered averages over $40^{\circ}-80^{\circ} \mathrm{N}$ and averages over the Northern Hemisphere north of $20^{\circ} \mathrm{N}$. In the previous subsection we mentioned that $\alpha_{p}$ also depends on the latitude at which the waves propagate upward. Therefore, we next examine where the zonal-mean upward wave-activity flux, which is proportional to $\left[\overline{v^{*} T^{*}}\right]$, is significantly correlated with $H_{100}$. The latitude- and pressuredependent correlation coefficient of $H_{100}$ with $\left[\overline{v^{*} T^{*}}\right]$ is shown in Fig. 4a. The highest correlation coefficient is found at $100 \mathrm{hPa}$ and $62.5^{\circ} \mathrm{N}(r=0.87)$. The decoupling between the total upward wave-activity flux at $100 \mathrm{hPa}$ and that in the troposphere (Fig. 2) is also visible in Fig. 4a: $H_{100}$ is not significantly correlated with $\left[\overline{v^{*} T^{*}}\right]$ in the lower and middle troposphere. We previously saw that the $s=1,2$ components of $H_{100}$ significantly correlate with the same wave-s components of $\left\langle\overline{v^{*} T^{*}}\right\rangle_{N H}$ at some level in the mid- and lower troposphere. Figure $4 \mathrm{~b}$ shows that the wave- 1 component of $H_{100}$ is significantly correlated with the wave- 1 component of $\left[v^{*} T^{*}\right]$ in the troposphere, between about $40^{\circ} \mathrm{N}$ and $60^{\circ} \mathrm{N}$. Note that the meridionally confined correlation coefficient maximum in the troposphere tilts poleward with height. A possible explanation for this correlation coefficient maxi- mum would be the presence of a waveguide, through which the wave- 1 activity is ducted to $100 \mathrm{hPa}$ (e.g., Karoly and Hoskins, 1982). Since a waveguide can be identified as a ridge in the refractive index field, we verify this by computing the climatological January-February pattern of the refractive index squared for $s=1$, which is shown in Fig. 5a. The wave-1 correlation coefficient maximum is roughly denoted by the dashed line. We see that the refractive index indeed has a ridge in the mid-latitude middle and upper troposphere, which suggests that the tropospheric correlation coefficient maximum in Fig. $4 \mathrm{~b}$ may be regarded as the signature of this tropospheric wave guide. To illustrate how the upper troposphere and lower stratosphere act as a low-pass filter for planetary wave activity from below, we show the refractive index field for $s=3$ in Fig. 5b. A mid-latitude vertical layer with negative values in the lower stratosphere emerges, of which the vertical extent increases with increasing wavenumber (not shown). For wavenumber 2 (Fig. 4c), a connection with the (lower) troposphere is found that is similar to that of wavenumber 1. A marked difference between Figs. 4c and $b$ is, that the area of maximum correlation coefficients in the troposphere is found at higher latitudes $\left(50-70^{\circ} \mathrm{N}\right)$ in Fig. 4c. (The distinct and very high maximum of $r=0.82$ at $1000 \mathrm{hPa}$ may not be very meaningful due to the extrapolation below ground.) This correlation coefficient maximum cannot be linked to an $s=2$ waveguide, since the refractive index field in this region is highly variable due to the presence of a zero-wind critical line, which is not sensitive to the zonal 

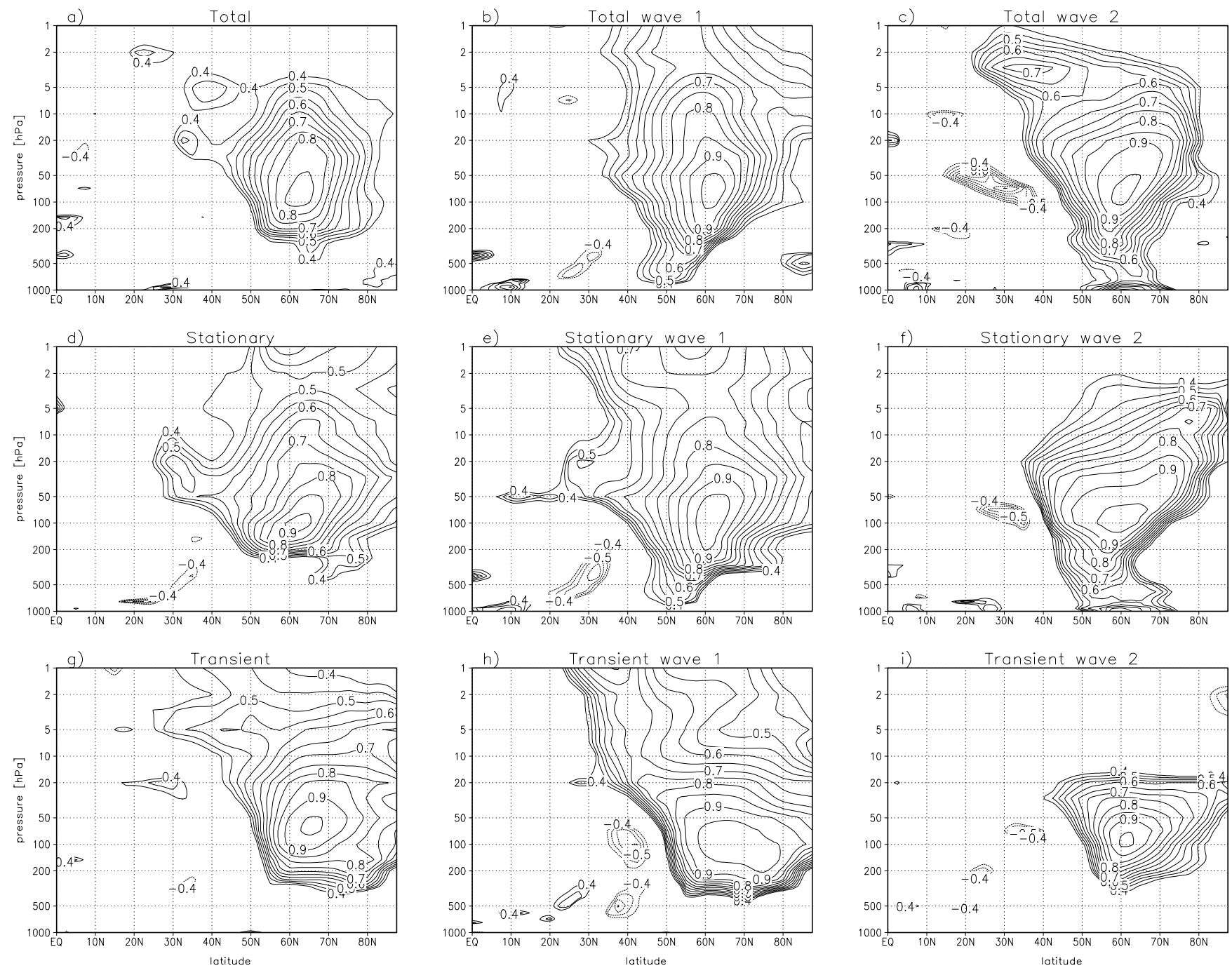

Fig. 4. Correlation coefficient of (a) $H_{100}$, (b) (c) the $s=1,2$ component of $H_{100}$, (d) the stationary component of $H_{100}$, (e) (f) the stationary $\mathrm{s}=1,2$ component of $H_{100}(\mathbf{g})$ the transient component of $H_{100}$, (h), (i) the transient s=1,2 component of $H_{100}$; with the same latitudeand pressure-dependent wave component of the zonal-mean eddy heat flux averaged over January-February. Correlation coefficients are calculated over 1979-2002, and only the areas with $>95 \%$ confidence levels are shown.

wave number of the refractive index. For wavenumber 2, the latitude of maximum correlation coefficients shifts equatorward with height above $100 \mathrm{hPa}$. For the wave-3 contribution to the heat flux, the link with the troposphere is absent and the area with significant correlation coefficients is much more confined (not shown). A further decomposition into stationary and transient wave components (Figs. 4d-i) reveals that the link with the (lower) troposphere is only statistically significant for the stationary part of the wave- 1 and wave- 2 contributions. The tropospheric meridional dipole structure in the stationary wave-1 correlation coefficient map (Fig. 4e) implies that the stationary wave- 1 component of $H_{100}$ is sensitive to the latitude of the tropospheric wave-1 source. If the source is located too far south, less wave activity is able to enter the mid-latitude waveguide and contribute to $H_{100}$. Such a dipole structure is not found in Fig. $4 \mathrm{f}$ for $\mathrm{s}=2$.
3.5 An alternative analysis of the interannual variability of $H_{100}$

In Sect. 2.3, we mentioned an alternative way of decomposing $H_{100}$, by noting that $\left[v^{*} T^{*}\right]$ equals the product of $r_{v, T}$ with $\sigma_{v}$ and $\sigma_{T}$ (Eq. 4). Subsequently, we assumed in Eq. (5) that $H_{100}$ can be approximated by $\tilde{H}_{100}$. To examine the accuracy of this approximation, we first compare the 24-year averages of both $\tilde{H}_{100}$ and $H_{100}$. This yields $14.1 \pm 0.4 \mathrm{~K} \mathrm{~m} \mathrm{~s}^{-1}$ and $15.1 \pm 0.5 \mathrm{~K} \mathrm{~m} \mathrm{~s}^{-1}$, respectively with a mean ratio of $0.94 \pm 0.02$. To see if $\tilde{H}_{100}$ and $H_{100}$ also have comparable interannual variability, we performed a linear regression of $H_{100}$ with $\tilde{H}_{100}$. The regression yields a high correlation coefficient $(r=0.85)$ and a regression coefficient $b=0.71 \pm 0.09$. We conclude that $\tilde{H}_{100}$ is indeed a useful approximation of $H_{100}$. We next linearize the deviation of 

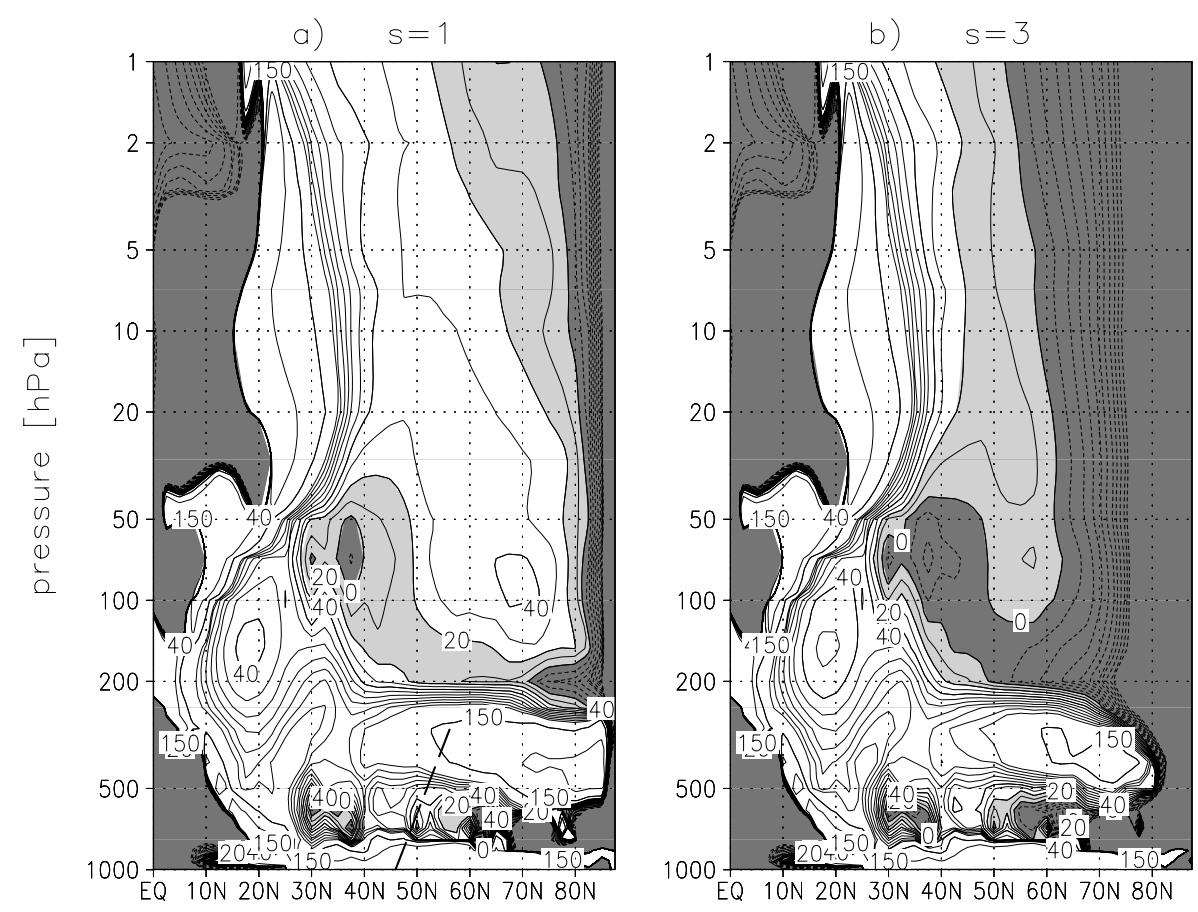

Fig. 5. Refractive index square $\mathrm{a}^{2} \mathrm{n}_{\mathrm{s}}^{2}$ in $\mathrm{m}^{2}$, based on the 1979-2002 average of the zonal-mean zonal wind during January-February, for (a) $\mathrm{s}=1$, and (b) $\mathrm{s}=3$. Except for the 150 and $300 \mathrm{~m}^{2}$ contours, contours are from -100 to $+100 \mathrm{~m}^{2}$, with an interval of $10 \mathrm{~m}^{2}$. Negative values are indicated by dark shading, positive values below $20 \mathrm{~m}^{2}$ by light shading. The $0,20,40$, and $150 \mathrm{~m}^{2}$ contours have been labeled, and the location of the $s=1$ correlation coefficient maximum is roughly denoted by the dashed line in (a).

Table 2. Linear regression of $H_{100}$ with $\sigma_{v}^{m} \sigma_{T}^{m} \Delta r_{v, T}, \sigma_{T}^{m} r_{v, T}^{m} \Delta \sigma_{v}$, and $\sigma_{v}^{m} r_{v, T}^{m} \Delta \sigma_{T}$ at $100 \mathrm{hPa}$. The linear regression is performed over 1979-2002. The 1979-2002 averages and standard deviations are for $\left\langle\overline{r_{v, T}}\right\rangle,\left\langle\overline{\sigma_{v}}\right\rangle$, and $\left\langle\overline{\sigma_{T}}\right\rangle$, respectively.

\begin{tabular}{lllll}
\hline & Regression coefficient & Corr. coeffient & $1979-2002$ average & $1979-2002$ stdev \\
\hline$\sigma_{v}^{m} \sigma_{T}^{m} \Delta r_{v, T}$ & $0.40 \pm 0.20$ & 0.39 & $r_{v, T}^{m}=0.23$ & 0.04 \\
$\sigma_{T}^{m} r_{v, T}^{m} \Delta \sigma_{v}$ & $0.07 \pm 0.09$ & 0.17 & $\sigma_{v}^{m}=10.4 \mathrm{~m} \mathrm{~s}^{-1}$ & $0.8 \mathrm{~m} \mathrm{~s}^{-1}$ \\
$\sigma_{v}^{m} r_{v, T}^{m} \Delta \sigma_{T}$ & $0.23 \pm 0.14$ & 0.34 & $\sigma_{T}^{m}=5.9 \mathrm{~K}$ & $0.7 \mathrm{~K}$ \\
\hline
\end{tabular}

$\tilde{H}_{100}$ from its $1979-2002$ mean as $\Delta \hat{H}_{100}$ (Eq. 6). The error $\Delta \hat{E}_{100}$ that arises from the linearization in Eq. (6) is remarkably small: a linear regression of $\Delta \tilde{H}_{100}$ with $\Delta \hat{H}_{100}$ yields $b=0.98 \pm 0.03$ and $r=0.99$. The difference between $\Delta H_{100}$ and $\Delta \hat{H}_{100}$ in Eq. (7) thus primarily results from $\Delta \tilde{E}_{100}$. We can use Eq. (7) to analyze the sensitivity of $H_{100}$ to the yearto-year variations in the effective phase difference $\left\langle\overline{r_{v, T}}>\right.$, as well as to the interannual variability of the effective amplitudes $<\overline{\sigma_{v}}>$ and $<\overline{\sigma_{T}}>$. The regression and correlation coefficients of the linear regression analysis of $H_{100}$ with the first three terms on the r.h.s. of Eq. (7) at $100 \mathrm{hPa}$ are given in Table 2. The results show that the interannual variability of $H_{100}$ is more sensitive to the $<\overline{r_{v, T}}>$ than to $<\overline{\sigma_{v}}>$ and $\left\langle\overline{\sigma_{T}}>\right.$. Therefore, a significant part of the year-to-year variability in $H_{100}$ is not determined by variability in the amplitude of the waves but by variability in the efficiency of the poleward heat transport, as represented by $<\overline{r_{v, T}}>$. We also note that the variability in $<\overline{\sigma_{T}}>$ affects $H_{100}$ more strongly than the variability in $<\overline{\sigma_{v}}>$.

\section{Summary and discussion}

We have studied the interannual variability of the stratospheric wave driving during $\mathrm{NH}$ winter, as quantified by $H_{100}$, being the January-February mean of the $40^{\circ}-80^{\circ} \mathrm{N}$ average of the total poleward heat flux at $100 \mathrm{hPa}$. For our analysis, we used 24 years (1979-2002) of ERA-40 reanalysis data from ECMWF. The results can be summarized as follows. We have examined the sensitivity of $H_{100}$ to several factors. The first factor is the strength of the total tropospheric wave source. It was found that $H_{100}$ is not 
significantly correlated with the total upward wave activity flux below $200 \mathrm{hPa}$. However, both the individual zonal wave- 1 and wave- 2 components exhibit significant vertical coupling between $100 \mathrm{hPa}$ and lower (as well as higher) levels. About $85 \%$ of the interannual variability of $H_{100}$ can be attributed to its $s=1,2$ components. However, the interannual variability of $H_{100}$ cannot be attributed to either of these individual wave components of the heat flux in the troposphere. Presumably, this is in part due to the statistically significant negative correlation coefficient that we found between the $s=1$ and $s=2$ components of $H_{100}$. This negative correlation coefficient is also observed on an intraseasonal timescale, in association with the leading mode of variability in the NH winter geopotential field, the Northern Annular Mode (NAM) (Hartmann et al., 2000). During high NAM index periods, with a stronger stratospheric polar vortex, the anomalous $s=1$ component of the heat flux at $100 \mathrm{hPa}$ was negative, and the anomalous $\mathrm{s}=2$ component was positive. During low NAM index periods, both anomalies were of opposite sign. Thus, the negative correlation coefficient we found on the interannual timescale is also observed on the shorter timescales. The wave- 1 contribution to $H_{100}$ was found to depend on the latitude of the wave-1 source. Particularly, if the tropospheric stationary wave- 1 source is located near $30^{\circ} \mathrm{N}$ instead of near $50^{\circ} \mathrm{N}$, significantly less wave activity is able to enter the mid-latitude waveguide and contribute to $H_{100}$.

Finally, another approach was followed, where the wave driving anomalies were separated into three parts: one part due to anomalies in the zonal correlation coefficient between the eddy temperature and eddy meridional wind, another part due to anomalies in the zonal eddy temperature amplitude, and a third part due to anomalies in the zonal eddy meridional wind amplitude. It was found that year-to-year variability in the zonal correlation coefficient between the eddy temperature and the eddy meridional wind is the most dominant of the three factors.

In the interpretation of our results, the assumption has been that wave activity always propagates upward, so that the source of the wave activity at $100 \mathrm{hPa}$ is situated below $100 \mathrm{hPa}$. For stationary waves, this is a reasonable assumption. However, transient waves can develop in the stratosphere as a result of purely stationary waves of sufficient amplitude emanating from the troposphere, as demonstrated by Christiansen (1999). Downward propagation of these stratospheric transients might affect $H_{100}$. However, we expect this to be only a minor influence, since the interannual variability of $H_{100}$ is dominated by stationary waves (Table 1 ), and transient wave activity is abundantly generated in the troposphere.

In the present study, the 1958-1978 period was omitted from the analysis. However, we have also analyzed the entire 1958-2002 period. The results were very similar, although the statistical significance was generally larger due to the longer period. As a result, Fig. 3a exhibited a significant correlation coefficient for $\mathrm{s}=1$ in the entire free troposphere. A remarkable difference with the 1979-2002 analysis was found for Fig. 3b, in which the level of maximum and significant correlation coefficient with $H_{100}$ was found to increase with increasing wavenumber $s=1-5$. The $s=1$ correlation coefficient decreased to statistically insignificant values of less than 0.3 in the upper stratosphere. In Fig. 4a, a clear equatorward displacement of a statistically significant correlation coefficient maximum was observed above $100 \mathrm{hPa}$, and in Fig. $4 \mathrm{e}$, the tropospheric dipole structure for $\mathrm{s}=1$ in Fig. $4 \mathrm{e}$ was more pronounced. Finally, for the 1958-2002 period, a significantly higher refractive index was observed in the mid-latitude stratosphere for a composite with positive $H_{100}$ anomalies exceeding one standard deviation than for a composite of negative $H_{100}$ anomalies exceeding one standard deviation. Such a significant signal could not be obtained for the 1979-2002 period, likely due to the smaller sample size.

One could argue that the results depend on the $40^{\circ}-80^{\circ} \mathrm{N}$ latitude window that is applied. However, replacing $H_{100}$ with the $\mathrm{NH}$ average of $\left[\overline{v^{*} T^{*}}\right]$ at $100 \mathrm{hPa}$ yields almost identical results. The present study has focused on the interannual variability of the stratospheric wave driving. We note that the factors that dominate the interannual variability may be different from the factors that dominate the trend. These issues will be subject of our further investigation.

Acknowledgements. The authors gratefully acknowledge the constructive suggestions that were made by the editor and three anonymous referees.

Edited by: P. Haynes

\section{References}

Andrews, D. G., Holton, J. R., and Leovy, C. B.: Middle atmosphere dynamics, Academic Press, 489 pp., 1987.

Austin, J., Shindell, D., Beagley, S. R., Brühl, C.,Dameris, M., Manzini, E., Nagashima, T., Newman, P., Pawson, S., Pitari, G., Rozanov, E., Schnadt, C., and Shepherd, T. G.: Uncertainties and assessments of chemistry-climate models of the stratosphere, Atmos. Chem. Phys., 3, 1-27, 2003, http://www.atmos-chem-phys.net/3/1/2003/.

Butchart, N., Scaife, A. A., Bourqui, M., de Grandpre, J., Hare, S. H. E., Kettleborough, J., Langematz, U., Manzini, E., Sassi, F., Shibata, K., Shindell, D., and Sigmond, M.: Simulations of antropogenic change in the strength of the Brewer-Dobson circulation, Clim. Dyn., 27, 727-741, doi:10.1007/s00382-006-01624, 2006.

Charney, J. G. and Drazin, P. G.: Propagation of planetary-scale disturbances from the lower to the upper atmosphere, J. Atmos. Sci., 18, 83-109, 1961.

Christiansen, B.: Stratospheric vacillations in a General Circulation Model, J. Atmos. Sci., 56, 1858-1872, 1999.

Eyring, V., Harris, N. R. P., Rex, M., Shepherd, T. G., Fahey, D. W., Amanatidis, G. T., Austin, J., Chipperfield, M. P., Dameris, M., Forster, P. M. De F., Gettelman, A., Graf, H. F., Nagashima, T., Newman, P. A., Pawson, S., Prather, M. J., Pyle, J. A., Salawitch, 
R. J., Santer, B. D., and Waugh, D. W.: A strategy for processoriented validation of coupled chemistry-climate models, Bull. Am. Meteorol. Soc., 86, 1117-1133, 2005.

Fusco, A. C. and Salby, M. L.: Interannual variations of total ozone and their relationship to variations of planetary wave activity, J. Climate, 12, 1619-1629, 1999.

Hartmann, D. J., Wallace, J. M., Limpasuvan, V., Thompson, D. W. J., and Holton, J. R.: Can ozone depletion and global warming interact to produce rapid climate change?, PNAS, 97, 1412-1417, 2000.

Haynes, P. H., Marks, C. J., McIntyre, M. E., Shepherd, T. G., and Shine, K. P.: On the "downward control" of extratropical diabatic circulations by eddy-induced mean zonal forces, J. Atmos. Sci., 48, 651-678, 1991.

$\mathrm{Hu}, \mathrm{Y}$. and Tung, K. K.: Possible ozone-induced long-term changes in planetary wave activity in late winter, J. Climate, 16, 30273038, 2003.

Karoly, D. and Hoskins, B. J.: Three-dimensional propagation of planetary waves, J. Meteorol. Soc. Japan, 60, 109-123, 1982.

Newman, P. A. and Nash, E. R.: Quantifying wave driving of the stratosphere, J. Geophys. Res., 105, 12 485-12 497, 2000.

Newman, P. A., Nash, E. R., and Rosenfield, J. E.: What controls the temperature of the Arctic stratosphere during the spring?, J. Geophys. Res., 106(D17), 19999-20010, 2001.

Polvani, L. M. and Waugh, D. W.: Upward wave activity flux as precursor to extreme stratospheric events and subsequent anomalous surface weather regimes, J. Climate, 17, 3548-3554, 2004.
Randel, W. J., Wu, F., and Stolarski, R.: Changes in column ozone correlated with the stratospheric EP flux, J. Meteorol. Soc. Japan, 80, 849-862, 2002.

Shepherd, T. G.: The middle atmosphere, J. Atmos. Sol.-Terr. Phys., 62, 1587-1601, 2000.

Siegmund P. C.: The generation of available potential energy: a comparison of results from a general circulation model with observations, Clim. Dyn., 11, 129-140, 1995.

Sigmond, M., Siegmund, P. C., Manzini, E., and Kelder, H.: A simulation of the separate climate effects of middle atmospheric and tropospheric $\mathrm{CO}_{2}$ doubling, J. Climate, 17(12), 2352-2367, 2004.

Simmons, A. J. and Gibson, J. K.: The ERA-40 project plan, ERA40 Proj. Rep. Ser. 1, 63 pp., European Centre for Medium-Range Weather Forecasts, Reading, UK, 2000.

Uppala, S. M., Kållberg, P. W., Simmons, A. J., Andrae, U., Da Costa Bechtold, V., Fiorino, M., Gibson, J. K., Haseler, J., Hernandez, A., Kelly, G. A., Li, X., Onogi, K., Saarinen, S., Sokka, N., Allan, R. P., Andersson, E., Arpe, K., Balmaseda, M. A., Beljaars, A. C. M., Van De Berg, L., Bidlot, J., Bormann, N., Caires, S., Chevallier, F., Dethof, A. ,Dragosavac, M., Fisher, M., Fuentes, M., Hagemann, S., Hólm, E., Hoskins, B. J., Isaksen, L., Janssen, P. A. E. M., Jenne, R., McNall, A. P. Y., Mahfouf, J.-F., Morcrette, J.-J., Rayner, N. A., Saunders, R. W., Simon, P., Sterl, A., Trenberth, K. E., Untch, A., Vasiljevic, D., Viterbo, P., and Woollen, J.: The ERA-40 re-analysis, Quart. J. R. Meteorol. Soc., 131, 2961-3012, doi:10.1256/qj.04.176, 2005. 